\title{
REPRESENTAÇÕES SOBRE A ESCRITA CIENTÍFICA EM VÍDEOS DO YOUTUBE
}

\author{
José Cezinaldo Rocha Bessa* \\ Nara Karolina de Oliveira Silva**
}

RESUMO: Partindo da necessidade de se problematizar questões relacionadas à leitura e à escrita no ensino superior no contexto das tecnologias digitais, este artigo objetiva analisar representações acerca da escrita científica expressas em vídeos do YouTube. Assumindo um olhar interpretativo e uma abordagem qualitativa, o trabalho centra-se no exame de dois vídeos do canal do Youtube "TCC Sem Drama" destinados a apresentar orientações sobre como escrever artigos científicos. A fundamentação teórica compreende ideias de pensadores e comentadores do Círculo de Bakhtin e trabalhos de estudiosos que abordam a escrita científica em perspectiva enunciativa e/ou sociorretórica. A análise aponta que a escrita científica é significada, nesses vídeos, como um produto com estrutura fixa, homogênea e generalizável, a ser apreendida por um conjunto de técnicas concebidas para cumprir, dentro de um espaço de tempo reduzido, uma mera tarefa/obrigação acadêmica.

PALAVRAS-CHAVE: Artigo científico; Canal do YouTube; Escrita científica.

\section{Introdução}

A relação do homem com as tecnologias digitais, especialmente em um contexto de proliferação e ampliação de redes sociais digitais, tem se revelado, dia após dia, um fenômeno fascinante. Podemos assumir, seguramente, que as tecnologias digitais, com suas mais diferentes plataformas, recursos e diversificadas funcionalidades de alcance global, modificaram profundamente os modos de ser, agir e de se relacionar da maioria das pessoas. O potencial delas reflete-se, por assim dizer, nas diversas esferas das atividades humanas (BAKHTIN, 2016), de modo a possibilitar significativos e inquestionáveis avanços à nossa vida em sociedade, muitos dos quais esperam ainda por ser melhor compreendidos.

\footnotetext{
* Doutor em Linguística e Língua Portuguesa pela Universidade Estadual Paulista Júlio de Mesquita Filho (Unesp), Campus de Araraquara. Professor Adjunto IV da Universidade do Estado do Rio Grande do Norte (Uern).

** Mestranda em Letras pelo Programa de Pós-graduação em Letras (PPGL). 
A esfera educacional também sente, ao menos de forma mais evidente em discursos de pesquisadores e educadores e em proposições de documentos oficiais (na BNCC, por exemplo), os reflexos da presença das tecnologias digitais que se encontram em plena expansão em nosso tempo. Fato é que especialistas (KENSKI, 2003, 2008; MORAN, 2007; VALENTE, 2014; RIBEIRO, 2020, entre outros) têm demonstrado, cada vez mais, que não se pode projetar planos e atividades para/na esfera educacional sem uma conexão com as tecnologias digitais e sem considerar as transformações e dinâmicas que elas possibilitam nos processos de ensinar e aprender nos dias de hoje. Embora as produções científicas (ver, por exemplo, KERSCH; MARQUES, 2017; AZZARI, 2019; DANTAS; LIMA, 2019) focalizem notadamente os níveis mais elementares de formação, essas transformações nos processos de ensinar e aprender se dão, naturalmente, nos diferentes níveis educacionais.

A propósito do ensino superior, que nos interessa aqui, são amplamente conhecidos também relatos de pesquisa e experiências acerca das tecnologias digitais em contexto formal de educação. Queremos crer, contudo, que nos ressentimos ainda, nos estudos da linguagem e da educação, de mais investigações e reflexões que se debrucem sobre questões relacionadas aos letramentos no ensino superior em contexto de educação informal, sobretudo focalizando o exame de blogs, sites, páginas, perfis no facebook e no instagram e canais no YouTube que se propõem a veicular conteúdos de natureza educativa, "de divulgação, de pesquisa, de apoio ao ensino e de comunicação" (MORAN, 1997, s/p).

Assim, inseridos em um contexto em que precisamos "encontrar caminhos para enfrentar a avalanche de informações buscando selecionar o que é relevante e estabelecer associações significativas" (OKADA, 2008, p. 37) e em que temos de lidar com a "circulação de informação globalizada, instantânea, apressada e, por vezes, imprecisa, duvidosa, quando não incorreta ou falsa” (BESSA; BERNARDINO, 2017, p. 175) em progressiva expansão, parece-nos fundamental que pesquisadores da linguagem se disponham a desenvolver estudos voltados à compreensão sobre como os estudantes do ensino superior e da pós-graduação tem se relacionado, inclusive em espaços de educação informal, com as tecnologias digitais em suas atividades de leitura e escrita de textos científicos. 
Uma possiblidade de contribuição na direção acima apontada é apresentada neste trabalho, em que objetivamos estudar representações sobre a escrita científica que circulam em vídeos do YouTube. Fundamentados em ideias de pensadores e de comentadores do Círculo de Bakhtin sobre o funcionamento dialógico e ideológico da linguagem e em trabalhos de estudiosos que abordam a escrita científica em perspectiva enunciativa e sociorretórica, nosso objetivo é analisar representações sobre a escrita científica expressos em vídeos do YouTube destinados a apresentar dicas e/ou orientações sobre como escrever/produzir artigos científicos. Considerando a larga audiência, que pode ser constatada com base no elevado número de visualizações e curtidas dos internautas, elegemos, como recorte para análise, o canal "TCC Sem Drama”.

De modo mais específico, analisaremos dois vídeos que abordam a escrita do artigo científico disponíveis no referido canal, procurando dar conta dos seguintes objetivos específicos: i) verificar como a escrita desse gênero acadêmico-científico é significada nos vídeos recortados para análise; ii) discutir como representações sobre a escrita científica construídas, nesses vídeos, podem ou não colaborar com a formação de jovens pesquisadores competentes e bem-sucedidos na escrita de artigos científicos.

Entendemos ser relevante submeter esse tipo de material com propósito educativo e de viés comercial disponível no universo digital a um exame mais crítico ${ }^{1}$ (no nosso caso em particular um exame de significações sobre a escrita científica), por compreendermos que esses vídeos acabam se constituindo como vídeoaulas (até mesmo de reforço) para muitos alunos da universidade que se encontram em situação de escrita de um Trabalho de Conclusão de Curso (TCC). E, nesse sentido, é fundamental termos em vista que o alto alcance e poder de influência dos conteúdos desses vídeos sobre os internautas pode contribuir para a construção de representações sobre a escrita científica que não correspondam à complexidade que constitui a prática de produzir textos científicos (MARTIN, 2018) e,

1 Trabalhos como os de Burton e Chadwick (2000) e Mcclure e Clink (2009) defendem uma perspectiva de letramento acadêmico que considera a necessidade de investimentos na formação de estudantes universitários quanto à capacidade de seleção, crítica e uso produtivo de fontes de pesquisa disponíveis no universo digital. 
por conseguinte, para disseminar equívocos sobre a prática de escrever textos dessa natureza na universidade, o que pode culminar em prejuízos para a formação científica de alunos/internautas.

Cabe-nos, pois, como estudiosos da linguagem, o desafio de desenvolvermos investigações sobre as redes de dizeres e sentidos em torno da leitura e da escrita que são produzidos em práticas sociais e estão em circulação nessas plataformas digitais, sem perder de vista, em nossas agendas de estudo, a necessidade de realizarmos um exame crítico desses dizeres e saberes e de problematizarmos possíveis implicações deles para as práticas pedagógicas e para a formação de estudantes/pesquisadores.

\section{Ancoragens teóricas}

Os postulados teóricos que dão sustentação ao presente trabalho estão estruturados, nesta seção, a partir de dois tópicos centrais: i) a linguagem na perspectiva do Círculo de Bakhtin; ii) a constituição e o funcionamento do gênero do discurso artigo científico.

\section{Apontamentos sobre a linguagem na perspectiva do Círculo de Bakhtin}

Para estudiosos das ciências da linguagem que, como nós, se propõem a assumir o pensamento de Bakhtin e seu Círculo como ponto de ancoragem central de suas investigações, deter-se na compreensão do funcionamento da produção social dos sentidos em enunciados concretos produzidos e em circulação nas esferas da atividade humana pressupõe ter em vista a linguagem como um fenômeno dialógico e ideológico.

Nessa perspectiva de enfrentamento da produção de sentidos, a linguagem não pode ser tomada como um objeto de estudo puramente linguístico. É preciso, conforme o Círculo de Bakhtin, considerar sua natureza viva, responsiva, axiológica. Nesse sentido, o nosso foco de atenção se volta não para o plano das relações lógicas, mas para o plano das relações dialógicas, concebidas como relações de sentidos, que se manifestam no nível do discurso (BAKHTIN, 2015). De acordo com esse direcionamento, a unidade de análise vai muito além da frase ou da oração descolada de um uso concreto, já que estas unidades são 
desprovidas de um contexto sócio histórico preciso e dos sujeitos que delas se utilizam, dos sujeitos que atualizam os sentidos em cada ato de dizer.

Como propõe Bakhtin (2015, 2016), a unidade de análise é o enunciado, uma vez que as trocas interativas entre os sujeitos se dão, na verdade, na forma de enunciados concretos, entendidos como unidades da comunicação discursiva. Em outras palavras, desde quando nascem e entram em relação com o mundo, as pessoas falam ou escrevem enunciados; elas se inserem, portanto, como um elo da cadeia ininterrupta de outros enunciados, já-ditos e antecipados. Isso ocorre porque a natureza complexa e multifacetada que caracteriza o funcionamento da linguagem pressupõe dizeres que se conectam com outros dizeres, num movimento em que cada troca comunicativa se realiza entrelaçada de palavras de outrem e povoada de acentos de outrem (BAKHTIN, 2016).

No dizer de Bakhtin (2016), o enunciado está repleto de relações dialógicas, "é pleno de ecos e ressonâncias de outros enunciados com os quais está ligado pela identidade da esfera da comunicação discursiva" (p.57). Embora nem sempre notada/observada, a manifestação dessas relações dialógicas se dá também na direção daquilo que o pensador russo denomina de resposta antecipada do interlocutor. Para ele, todo enunciado está orientado socialmente e pressupõe a figura de um interlocutor presumido ou destinatário, que “tem várias faces, vários perfis, várias dimensões” (BRAIT; MELO, 2016, p. 71).

Assumir a ideia de uma orientação social implica ter em conta que a figura do ouvinte/destinatário constitui elemento fundamental do funcionamento complexo dos enunciados, já que estes, ao serem manifestos, estão impregnados também com as "avaliações do seu ouvinte ou do seu auditório em potencial, mesmo que o pensamento sobre o ouvinte não tenha ocorrido ao falante" (VOLOCHÍNOV, 2019, p. 274).

Considerar a linguagem como esse fenômeno complexo, multifacetado e como manifestação de valores nos intercâmbios comunicativos que orientam a vida social (MEDVIÉDEV, 2012) é partir da compreensão de que ela é constitutiva dos sujeitos. Nessa linha de compreensão, a produção de sentidos corresponde a uma atividade discursiva que se realiza sempre conforme as esferas do agir humano e os sistemas de valores dos sujeitos. Nesse sentido, "com a ajuda da linguagem/língua, criam-se e formam-se os sistemas 
ideológicos (a ciência, a arte, a moral, o direito), e ao mesmo tempo a língua cria e forma a consciência do homem" (VOLOCHÍNOV, 2019, p. 264).

Conforme concebe Bakhtin (2016), vivemos em um universo de signos (verbais, não-verbais, de múltiplas semioses) carregados de valores, em que os enunciados que produzimos, nas mais diversas esferas do agir humano, estão sempre povoados de dizeres de outrem e de acentos valorativos desses outros, nem sempre harmônicos, mas em movimento de embate e tensões, uma vez que a linguagem reflete e refrata os valores dos sujeitos e a realidade em sua dinâmica de transformação (VOLOCHÍNOV, 2017).

Desse modo, o enunciado carrega não só uma entoação avaliativa, mas também expressa e orienta certos modos de ver/compreender o mundo e não outros, logo, "todo discurso busca na verdade monopolizar os sentidos que cria, porque, ao dizer, o locutor procura tornar aceito o seu tom avaliativo - não o do outro" (SOBRAL, 2009, p. 46). Conquanto seja permeado por outras vozes e outros acentos valorativos, ao se expressar, o enunciador coloca em cena o seu posicionamento valorativo/axiológico sobre o dizer que enuncia, considerando, pois, que ele ocupa uma posição social determinada pelas condições de sua existência social (VOLOCHÍNOV, 2017).

Como produto da interação verbal e situados em um dado contexto, de um determinado meio social organizado, os enunciados que produzimos estão, de acordo com Bakhtin (2016), sempre inevitavelmente em contato com outros enunciados que já carregam determinados acentos valorativos, com os quais interagem e se ressignificam, constituindo, portanto, o elo de dizeres que caracteriza a cadeia da comunicação discursiva.

As considerações aqui tecidas, a partir do pensamento de Bakhtin e seu Círculo e de comentadores desse Círculo, sobre linguagem, enunciado, relações dialógicas e valores ideológicos nos permitem construir uma compreensão mais profunda sobre como são orquestrados os dizeres com os quais interagimos e os valores que eles expressam. Assim, compreender um enunciado na perspectiva bakhtiniana é também realizar uma avaliação sobre ele, refletir sobre a sua natureza dialógica e ideológica, uma vez que não se trata tão somente de resgatar os sentidos passados que ecoam, mas, sobretudo, buscar apreender, 
na trama de dizeres, as possibilidades outras de significação/sentidos que cada ato de dizer de um dado sujeito expressa e põem em circulação.

\section{O gênero artigo científico: funcionamento e constituição}

Nas práticas de leitura e escrita do universo acadêmico-científico, o artigo científico é não só " [...] o gênero de maior visibilidade e centralidade em boa parte das disciplinas. (BEZERRA, 2015, p. 02), como também o gênero discursivo “[...] por excelência da atividade de produção e divulgação do conhecimento" (BESSA, 2016a, p. 87). O artigo científico é concebido aqui como gênero discursivo de natureza complexa, que reflete, em seu conteúdo temático, no seu estilo e em sua construção composicional, as condições e finalidades comunicativas da esfera da atividade humana na qual é produzido e circula (BESSA, 2016a).

Nessa linha de compreensão e em diálogo com o pensamento de Garcia Negroni (2008), o artigo científico constitui um espaço de dialogismo enunciativo. Isso implica dizer que, em um artigo científico, o seu autor se posiciona em relação à comunidade científica para a qual se dirige mediante a apresentação dos resultados obtidos em sua investigação. Assim, a finalidade principal de um artigo científico é "reportar, para um público especializado [...], os resultados novos de uma pesquisa/estudo sobre um tema específico visando a contribuir com a construção do conhecimento [...]” (BESSA, 2016a, p. 90-91).

Como se trata de um gênero discursivo de uma esfera especializada, que implica a produção e a circulação de textos com estrutura fortemente convencionalizada e características muito restritivas (BOSIO, 2018), o artigo científico é um tipo relativamente estável de enunciado (BAKHTIN, 2016), que revela, portanto, uma forte tendência de padronização e, por conseguinte, menos liberdade criativa para quem o produz (BESSA, 2016a). Isso não significa, contudo, que o produtor não possa encontrar "brechas" nos "grilhões do formalismo" acadêmico-científico (CORACINI, 2007) e imprimir marcas de sua individualidade/subjetividade (GARCIA NEGRONI, 2008) na escrita do artigo científico. Hyland (2014, p.1) também compartilha dessa visão sobre a subjetividade na escrita de textos científicos, quando diz que "a expressão de opiniões pessoais e avaliações é uma característica 
da interação humana e, a despeito do aspecto impessoal aparente, também central para a escrita acadêmica".

Embora documentos de viés mais técnico-normativo como a ABNT NBR 6022:2018 prescrevam que o artigo científico seja constituído de três estruturas mais gerais denominadas de "elementos pré-textuais, elementos textuais" (introdução; desenvolvimento e conclusão) e "elementos pós-textuais", a literatura mais recente sobre escrita científica, especialmente aquela desenvolvida pelos estudos da linguagem, tem focalizado a estruturação do artigo científico com base, especialmente, no que se tem denominado de modelo de organização sociorretórica de gêneros, na linha dos estudos de gêneros iniciada por Swales (1990).

Na perspectiva de modelo de organização retórica de gêneros, o artigo científico se apresenta como um gênero cuja configuração sociorretórica revela variações conforme as culturas disciplinares (BERNARDINO, COSTA, 2017). O trabalho de Motta-Roth e Hendges (2010), que se encontra ancorado em princípios teóricos da análise de gêneros discursivos acadêmicos na linha proposta por Swales e com a qual dialogamos em nossos trabalhos (BESSA, 2016a; 2018a), adota a seguinte organização sociorretórica para os artigos acadêmicos: introdução, revisão de literatura, metodologia, análise e discussão dos resultados e conclusão.

Esse nosso modo de entender o funcionamento e a estruturação do artigo científico aqui sintetizado se coloca em consonância com o pressuposto de que "cada disciplina cria novas formas de ver o mundo, novas formas de pensar suas problemáticas e novas formas de atuar nele"2. (BAZERMAN, 2014, p. 11) e de que "[...] a escrita não é uma habilidade única e generalizante, que se aprende de uma vez e para sempre, mas que é necessário levar em consideração as convenções próprias de cada disciplina para poder

2 Tradução do original em espanhol: "Cada disciplina genera nuevas formas de ver el mundo, nuevas formas de pensar sus problemáticas y nuevas formas de actuar en él” (BAZERMAN, 2014, p. 11). 
incorporar-se a ela [...]"3 (NAVARRO, BROWN, 2014, p. 66-67). Nesse sentido, assumimos, neste trabalho, que o artigo científico apresenta uma forma de organização e funcionamento que se ajusta às convenções próprias da esfera acadêmico-científica e suas culturas disciplinares, às especificidades das condições concretas de sua produção, recepção e circulação, ao estatuto do produtor ${ }^{4}$ na atividade científica e ao estilo particular/individual de escrita do pesquisador.

\section{Metodologia}

Dada a complexidade inerente à atividade de produção de sentidos e a especificidade do objeto do qual se ocupa as ciências humanas (BAKHTIN, 2017), nosso olhar de pesquisador é orientado pela pesquisa de natureza interpretativa, como a concebem Laville e Dionne (1999). Em consonância com o olhar interpretativo, adotamos uma abordagem qualitativa, afinal, como estudiosos da linguagem, estamos interessados no movimento dos sentidos que os enunciados recortados para exame expressam.

O corpus de análise deste estudo é constituído por dois vídeos que se destinam a “oferecer orientações e/ou dicas” sobre a escrita do gênero artigo científico. Selecionamos os vídeos do canal "TCC Sem Drama”, um dos canais brasileiros voltados para a escrita científica mais acessados (com quase 1 milhão de visualizações) da plataforma YouTube. Os vídeos selecionados para análise foram os seguintes: "Artigo Científico Pronto em 5 Passos" (Vídeo 1) e "Artigo Científico Pronto em 5 Passos" (Vídeo 2), que se propõem a apresentar uma sequência de cinco passos "práticos" para se produzir um artigo científico de "qualidade e em pouco tempo".

Para os propósitos de nosso estudo, entendemos ser fundamental reportar aspectos da dimensão contextual da produção dos vídeos analisados. É preciso considerarmos que o canal “TCC Sem Drama”, com aproximadamente 10 anos de existência, faz parte de um

\footnotetext{
${ }^{3}$ Traduçaõ do original em espanhol: "[... la escritura no es una habilidad única y generalizable, que se aprende de una vez y para siempre, sino que será necesario tomar en cuenta las convenciones propias de cada disciplina para poder incorporarse a ella [...]" (NAVARRO e BROWN, 2014, p. 66-67).

${ }^{4}$ Seguindo a linha de Boch e Grossman (2002), assumimos o estatuto do produtor (se iniciante, se especialista, por exemplo) como um dos aspectos fundamentais para compreendermos as práticas de escrita científica. 
projeto denominado "TCC Sem Drama", do professor Amilton Quintela, que se propõe a produzir conteúdos de orientação de trabalhos acadêmicos por meio de internet. O projeto inclui, por exemplo, a oferta de cursos e/ou treinamentos pagos que podem ser acessados, em área restrita, no blog do projeto, bem como a disponibilização gratuita de vídeoaulas em suas plataformas como canal no YouTube, perfil no facebook e no instagram, utilizadas, conjuntamente com outros enunciados, como forma estratégica de promoção do projeto.

É preciso considerarmos ainda que o projeto, centrado em boa medida nos treinamentos e/ou cursos oferecidos no blog, assume o compromisso de "apresentar dicas" e “ensinar técnicas" que ajudem os interessados de "qualquer área do conhecimento", interlocutores imediatos, a produzirem um TCC (que pode ser uma monografia, um artigo científico, uma dissertação de mestrado, dentre outros) de forma "mais rápida e fácil". Com essa fórmula, o projeto assegura a garantia de êxito dos cursistas em suas produções, que é atestada, conforme notifica o blog, pelo desempenho de alunos com "notas superiores a 9,5 em um total de 10 pontos".

Isso posto, cabe-nos destacar como operacionalizarmos a análise. Além de assistirmos os vídeos diversas vezes, transcrevemos e fizemos leitura e releitura dos textos transcritos $^{6}$. Com base nessas leituras interpretativas, à luz do referencial teórico mobilizado, fomos construindo nossa compreensão das representações que os vídeos, como enunciados concretos, expressam sobre a escrita científica. O produto resultante desse exercício interpretativo trazemos na seção a seguir.

Antes, porém, de passarmos à análise, é importante esclarecermos que, em sua composição, os vídeos selecionados comportam momentos em que o enunciador realiza divulgação do projeto "TCC Sem Drama”, emite comentários pessoais sobre recursos das

${ }^{5}$ Mais detalhes podem ser conferidos nesse endereço: http://www.comomontartcc.com.br/. Acesso em: 14 abr. 2020.

${ }^{6} \mathrm{Na}$ transcrição dos vídeos, seguimos as convenções de transcrição adaptadas de estudos da Análise da Conversa de Sacks, Schegloff e Jefferson (1974), com incorporações de Loder e Jung (2009), na proposta apresentada no trabalho de Atallah e Nogueira (2013). 
gravações e suas vestimentas, além de inserir trechos de vídeos de humor como comentários metaenunciativos. Como esses elementos não se mostraram produtivos para a análise desenvolvida, eles não aparecem nos excertos que recortamos para ilustrar nosso trabalho analítico. Convém assinalar, inclusive, que, nos excertos reproduzidos ao longo da análise, operamos cortes e destacamos, em negrito, alguns trechos dos dizeres do enunciador que consideramos dispensáveis para os propósitos do que pretendíamos explorar.

\section{Representações sobre a escrita científica em vídeos do YouTube do canal TCC Sem}

\section{Drama}

Nesse momento, nosso foco de atenção se volta ao exame de representações sobre a escrita científica que circulam em vídeos do YouTube do canal "TCC sem Drama". Para darmos conta de como a escrita científica é significada nesses vídeos, concentramos nosso olhar sobre os posicionamentos axiológicos expressos pelo sujeito enunciador ao reportar à definição e as finalidades do artigo científico e ao apresentar/propor 05 passos para a escrita desse gênero do discurso. Para este estudo, selecionamos, conforme já antecipado, dois dos vídeos do canal que se propõem a abordar especificamente o artigo científico, quais sejam: “Artigo Científico Pronto em 5 Passos” (Vídeo 1) e "Artigo Científico Pronto em 5 Passos" “(Vídeo 2).

Um direcionamento inicial da análise foi compreender o título do canal "TCC Sem drama". Considerando que a proposta do canal gira em torno da ênfase nos resultados e na venda de soluções rápidas e fáceis, para alunos que, geralmente, se encontram com prazos apertados e/ou que enfrentam dificuldades para escrever um TCC, podemos entender também os sentidos expressos no título do canal. Sabendo que esses são os "ingredientes" centrais que orientam a produção e a constituição dos vídeos por nós analisados, entendemos que a escolha do título do canal acaba funcionando como um convite/apelo ao aluno que está em situação "complicada", "dramática” no processo de escrita de seu TCC.

Com base nessa compreensão, passemos ao exame dos vídeos recortados. O primeiro deles, com duração de 7 minutos e 38 segundos, se propõe a dar conta de dois dos cinco passos - montar uma estrutura básica e montar uma introdução - propostos pelo 
enunciador, para "guiar a produção de um artigo científico", com vistas a "evitar que o estudante tenha que passar semanas e até mesmo meses" escrevendo seu TCC, o que demonstra já a ideia de que a escrita do artigo científico pode ser reduzida a alguns poucos passos que venham assegurar o êxito em sua produção em um curto espaço de tempo.

Antes de anunciar os passos, o enunciador realiza uma breve apresentação de si e faz um chamamento para que o internauta continue assistindo o vídeo, assegurando-lhes que oferecerá a "solução" de apresentar uma estrutura de 5 passos que podem guiar a produção do artigo científico. Em seguida, ele anuncia que vai passar a apresentar essa estrutura, explicitando, antes de tudo, o que seria o artigo científico e sua finalidade para o meio acadêmico-científico, conforme consta no excerto a seguir:

(1)

[...] Se você tem que fazer um artigo científico, primeiro, já sinta um privilégiado, PORQUÉ? Porque o artigo científico é o menor trabalho acadêmico em termos de conteúdo $\uparrow$, Ele é o que tem o menor número de páginas, então a BOA NOTÍCIA É? Você vai escrever MENOS. Além disso, os artigos científicos são muito mais direcionados $\uparrow$, são muito mais práticos $\uparrow$, têm um volume menor de conteúdo... mas são muito objetivos $\uparrow$, e isso é legal. [...] $\mathrm{O}$ artigo científico é um modelo de TCC [...] trabalho de conclusão de curso, é o nome genérico. O artigo científico é um dos modelos, então o TCC pode ser um artigo, pode ser uma monografia, pode ser uma dissertação [...] Por que que faz artigo? Para que ele serve? Eu poderia te dizer, por exemplo, que ele serve para desenvolver a ciência, ou atualizar o conhecimento científico, ou impactar a realidade, mas quer saber de uma coisa? Para gente que está no meio acadêmico o artigo científico serve para dar notoriedade ao AUTOR [...] impulsionar a autoridade do autor $\uparrow$, mas, no seu caso você vai fazer um artigo científico para concluir sua graduação, sua pós-graduação... (Vídeo 1)

Como podemos observar, o excerto acima é marcado de acentos valorativos do enunciador que indicam sobre a maneira como ele concebe o artigo científico e a finalidade desse tipo de enunciado. A proposta de "vender" a ideia de que escrever um artigo científico é um "privilégio", pelo fato de parecer um gênero mais prático e mais simples do que outros da esfera acadêmico-científica, é colocada em evidência nos dizeres do produtor. Isso se encontra marcado, na materialidade linguística, por alguns índices, especialmente por marcadores de intensidade: "o menor" trabalho acadêmico em termos de conteúdo, 
“menor número" de páginas, escrever "menos”, têm "um volume menor" de conteúdo, "mas são muito" objetivos.

Com essa estratégia, o enunciador procura se aproximar de seu potencial interlocutor (no caso, seus potenciais consumidores) expressando a ideia de que é possível simplificar a escrita do artigo científico. Para tanto, recorre ao argumento de que se trata de um texto com "menor volume de conteúdo" e de "páginas". Na apreciação do enunciador, escrever um artigo científico representa a possibilidade de "escrever menos", logo se trataria de uma atividade menos trabalhosa, o que reforça, em certo sentido, a ideia de que o momento de escrever, também na universidade, se associa a "situações desagradáveis" (MACHADO, 2007).

Cumpre observamos ainda que, embora indique diversas finalidades relativas à escrita de um artigo científico, o produtor acaba colocando acento em duas delas. Ele expressa, com certa tonalidade de desprezo (a considerar o modo como se expressa e faz movimentos com o corpo), que a finalidade principal que move os pesquisadores, na escrita de artigos, é o reconhecimento pela comunidade acadêmica: "Para a gente que está no meio acadêmico, o artigo científico serve para dar notoriedade ao autor [...] serve muito para impulsionar a autoridade do auto". Com esse ponto de vista valorativo, o enunciador contribui para acentuar uma imagem negativa, qual seja: a de que, na atividade de escrita de artigos, o pesquisador é movido, antes de tudo, pelo reconhecimento dos pares. Nos dizeres do enunciador, é como se o que importasse, para o pesquisador, fosse fundamentalmente a busca pela notoriedade, por se tornar celebridades, o que configuraria uma espécie de narcisismo acadêmico (AVELINO, 2017) generalizado.

Ademais, ele expressa a ideia de escrita do artigo científico como cumprimento de uma obrigação: "mas, no seu caso, você vai fazer um artigo científico para concluir sua graduação, sua pós-graduação". Fica evidente que o enunciador concebe a escrita do artigo científico como uma tarefa meramente burocrática, cujo fim é a obtenção de uma nota que possibilitará ao aluno a conclusão do curso. Deixa de se considerar que, para além de se solicitar a produção de textos para fins avaliativos, é possível extrapolar o contexto de sala de aula e de elaboração de trabalho de conclusão de curso e conceber a produção do texto 
para a divulgação do conhecimento científico (QUEIROZ, BESSA, JALES, 2015). Poderse-ia sustentar, portanto, a defesa da obtenção de nota, porém sem perder de vista a finalidade de socialização do conhecimento que caracteriza o fazer científico (DAY, 2001).

Cabe assinalarmos ainda que o acento valorativo sobre a escrita do artigo científico como uma atividade meramente por obrigação produz também a representação de que escrever um artigo científico cuja finalidade seja contribuir para "desenvolver a ciência, atualizar o conhecimento científico" ou "impactar a realidade" não constitui um compromisso de todo sujeito/pesquisador que se envolve com a atividade científica, o que denota, assim, que essa não deva ser uma preocupação de seus potenciais interlocutores/consumidores, para os quais importaria tão somente se concentrar na tarefa de concluir o curso.

No final das contas, constrói-se a impressão de que o enunciador está pouco ou nada preocupado com a contribuição que uma pesquisa de qualidade pode e deve apresentar, indo de encontro ao que Severino (2002) defende sobre o que se espera da produção do conhecimento no espaço da universidade. Nesse sentido, a receita apresentada pelo enunciador, de seguir uma "estrutura básica", composta de 5 passos, vai ao encontro de o aluno poder fazer o básico e ser aprovado em seu curso, de modo a satisfazer os interesses em jogo.

Podemos observar, na continuidade do vídeo, que o enunciador reforça não só o efeito de simplificação da escrita, como também produz um efeito de generalização do ato de escrever, quando se reporta ao primeiro dos 5 passos. Nesse primeiro passo, ele expressa um posicionamento advogando a existência de uma única receita para "começar a escrita de todo trabalho acadêmico", partindo da "certeza de que todo trabalho científico tem que começar pelo que a gente chama de estrutura básica".

(2)

Primeiro passo para produzir um artigo científico é começar por onde TODO trabalho acadêmico tem que começar $\uparrow$ ((fala mais forte e pausada, com convicção)) [...] A outra grande certeza é de que todo trabalho científico tem que começar pelo que a gente chama de uma estrutura básica. [...] Amilton o que que é uma estrutura básica? A estrutura básica é o tema delimitado, um problema de pesquisa, uma questão a respeito desse tema, objetivo geral e objetivos específicos [...]. Não comece a escrever nada, não pesquisa referencial teórico enquanto essa estrutura não estiver montada $\uparrow$ (Vídeo 1) 
No excerto 2, podemos perceber claramente a ideia de encarar a escrita como uma receita, ou seja, uma fórmula a ser seguida pelos potenciais interlocutores/consumidores, que, no caso, é a denominada "estrutura básica” proposta pelo enunciador. Para convencer o seu interlocutor da eficácia dessa técnica, ele sustenta o argumento de que fugir dessa estrutura básica representa perder tempo: "não comece a escrever nada, não pesquisa referencial teórico enquanto essa estrutura não estiver montada".

Se, por um lado, concordamos que o êxito de um projeto de pesquisa e da escrita dele decorrente depende, por exemplo, da delimitação do tema e da formulação do problema de pesquisa, por outro lado, compreendemos que realizar leituras e pesquisar referencial teórico não necessariamente devam ser postergadas até que se tenha definido tudo em um projeto de escrita de textos científicos. Dentro de situações autênticas de escrita científica, o envolvimento com leituras e a realização de uma pesquisa bibliográfica constituem, como depreendemos de Machado (2007), não somente condições necessárias como atividades determinantes para que possam organizar as ideias e formalizar melhor, por escrito, a proposta de pesquisa.

Esse argumento suscitado pelo enunciador não satisfaz necessariamente as condições concretas de uma escrita científica que siga um percurso de maturação e de sistematização de ideias até sua materialização na escrita, pois se volta a satisfazer as condições de um projeto de escrita a ser efetivado em curto espaço de tempo, em que a pressa para o cumprimento dos prazos se apresenta como a bússola orientadora da escrita.

O posicionamento de tomar a escrita como uma receita e a produção do artigo como uma construção textual simples é reforçado ainda quando o enunciador aborda o segundo passo, que diz respeito às orientações sobre a elaboração da seção de "introdução", conforme podemos ver no excerto que segue: o que eu digo ? (.) < finge que você escutou, finge que você vai considerar $>$, mas escreve a sua

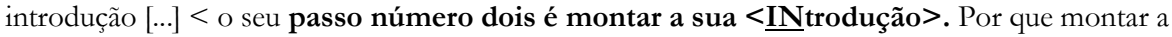
introdução? [...] porque a introdução pode ser <um - bom - roteiro - para - o - resto - do seu - trabalho ... para todo desenvolvimento. $\mathrm{O}>$ artigo científico $<$ tem três, $\underline{\text { SÓ }}$ três 
elementos textuais: introdução, desenvolvimento e conclusão. $\underline{\mathrm{NO}}$ desenvolvimento estão os capítulos ? e :: a introdução? É uma reunião de elementos [...] (Vídeo 1)

No excerto 3, percebemos, inicialmente, que o enunciador parte da estratégia de negar o trabalho de orientadores de TCCs, a quem é imputada a responsabilidade de "desorientar" os alunos, pelo fato de encaminharem "a introdução para o final" do processo de escrita. Como forma de mostrar um outro caminho possível, mais viável na perspectiva assumida, para a concretização do trabalho, o enunciador propõe que os alunos devam ignorar a lógica dos orientadores e seguir o roteiro que pressupõe começar pela "introdução". Nesse sentido, o direcionamento é seguir a estrutura que ele defende, considerada mais simples e padrão.

Essa receita mais simplificada de escrita do artigo pode ser também observada quando ele aponta que o "artigo científico tem três, só três elementos textuais, introdução, desenvolvimento e conclusão". Como demonstra uma vasta literatura sobre escrita acadêmico-científica, a escrita de artigos científicos não segue necessariamente, em todas as áreas do conhecimento, o modelo "Introdução-Desenvolvimento-Conclusão" (IDC). De acordo com Day (2001) e Aragão (2011), diversas áreas do conhecimento seguem uma outra estrutura na produção de seus artigos, qual seja: "Introdução-Métodos-Resultados-Discussão” (IMRD). Isso sinaliza que as orientações expressas nesse vídeo desconsideram, com o propósito de simplificar a escrita do artigo, as variações nas formas de construir conhecimento e escrever inerentes às culturas disciplinares (BAZERMAN, 2014).

$\mathrm{Na}$ linha do que apontamos no parágrafo anterior, não podemos deixar de nos questionar sobre a visão genérica de que o artigo científico apresenta somente 3 elementos “(introdução, desenvolvimento e conclusão)", até porque não deve ser surpresa, sobretudo para um aluno/internauta mais atento, que os artigos apresentam, geralmente, uma estrutura com mais elementos. Basta considerarmos que uma seção de "métodos" é, inclusive, obrigatória em muitas áreas do conhecimento (ARAGÃO, 2011), e não apenas mais um dos elementos da "introdução", como propõe o enunciador do vídeo ora analisado. Logo, sustentar que são tão somente 3 elementos sinaliza uma forma de reafirmar a representação 
de que escrever um artigo científico não é tão difícil assim. Essa ideia aparece reafirmada, novamente, na apresentação dos elementos constitutivos da seção 'introdução', conforme ilustrados na figura a seguir:

Figura 1- Elementos da introdução de um artigo científico

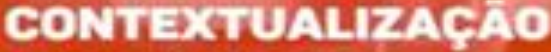

JUSUIFIGATHA

PROBLEMA DEPESOUISA

OBNETIO EERAL

OBNETWOS ESPECIFICO

METODOLOCHA

ESTRUTURA DE CARTIULOS

Fonte: Figura recortada do vídeo 1

O recorte apresentado nessa figura, que é parte do que o enunciador expressa sobre o segundo passo, manifesta o modo como ele concebe a estrutura de uma "introdução" de artigo científico. Nas palavras expressas pelo enunciador, a seção de "introdução" do artigo científico apresenta essa estrutura padrão, resultado de "uma reunião de elementos": "contextualização, justificativa, problema de pesquisa, objetivo geral, objetivos específicos, metodologia e estrutura de capítulos".

Se, por um lado, é significativo o fato de que o enunciador reporte elementos que são considerados indispensáveis para a construção de uma "introdução", é, por outro lado, questionável a representação de que o artigo científico revela uma estrutura fixa, da qual se possa prescindir apenas do "problema de pesquisa", como sustenta o enunciador. Não é novidade, entre pesquisadores da escrita científica (BESSA, 2016a), que a metodologia de uma pesquisa é, em diversas áreas do conhecimento, uma seção específica, que inclusive, a depender dos propósitos da investigação, não pode se limitar a uma descrição breve, como é sugerido na exposição do enunciador. 
É claro que não estamos defendendo que, em determinadas pesquisas, não seja plenamente possível apresentar/descrever a metodologia da pesquisa na seção de "introdução", tampouco que a descrição metodológica apresentada nessa seção não possa ser breve, especialmente quando se trata de um trabalho de conclusão de curso de graduação. Questionamos, na verdade, o fato de se sustentar uma representação de "introdução" como estrutura fixa, que não considera, por exemplo, as especificidades da natureza da pesquisa e as culturas disciplinares (HYLAND, 2004; NAVARRO; BROW, 2014).

O que apontamos acima sobre a metodologia se aplica, em boa medida, também à ideia de uma "estrutura de capítulos", sobre a qual o enunciador coloca um acento muito forte, conforme vemos a seguir:

[...] ? pensar os objetivos? você vai descrever brevemente a sua MEtodologia e fazer uma coisa que é MUITO, MUITO: importante e MUITO aluno esquece . você vai montar uma EStrutura de capítulos > O que é uma estrutura de capítulos? < é um texto - pequeno em que você diz QUAIS são OS tópicos que serão abordados em CADA um dos capítulos do desenvolvimento do seu trabalho . ISSO já na introdução, POR ISSO < a introdução serve como um grande para o seu desenvolvimento do conteúdo do artigo científico $>$ (Vídeo 1)

Os índices linguísticos destacados em negrito no excerto 4 indicam muito bem o quanto, para o enunciador, o elemento "estrutura de capítulos" é concebido como um item indispensável na produção de um artigo científico. Quando expressa que "a estrutura de capítulos" é um elemento que "muito aluno esquece", o enunciador explicita de forma mais contundente essa concepção, que reforça a ideia de uma estrutura fixa da seção de "introdução".

Assim, o enunciador parece desconhecer que esse tipo de elemento é típico de gêneros acadêmicos como monografia, dissertação de mestrado e tese de doutorado, não se constituindo, contudo, elemento necessariamente indispensável na produção de um artigo científico. Logo, não é novidade encontrarmos artigos científicos, nas diversas áreas do conhecimento, que não apresentam uma "estrutura de capítulos", como podemos depreender a partir do estudo de Bernardino e Costa (2016). 
Isso mostra como o enunciador reafirma, nesses seus dizeres, uma representação de escrita científica que assume o artigo científico como um gênero marcado basicamente por uma estrutura fixa, padrão e generalizável a todas as áreas do saber. Isto é, seus dizeres desconsideram que, como aponta Hyland (2004), as diferenças que caracterizam as práticas de escrita são mais significativas que as similitudes gerais.

Já o segundo vídeo, intitulado "Artigo científico pronto em 5 passos", que tem duração de 7 minutos e 49, segundos, se propõe a dar continuidade com as "diretrizes para montar o caminho básico para montar o seu artigo científico”. Nesse vídeo, o foco são os outros três passos dos cinco anunciados: 3) roteirizar os capítulos, 4) copiar os tópicos interessantes ao pesquisar o referencial teórico, e 5) escrever sem procrastinar.

$\mathrm{O}$ enunciador assume, de partida, que "qualquer trabalho acadêmico, aqui, em Marte, Júpiter, em qualquer lugar do mundo, um trabalho acadêmico começa pela estrutura básica", e enfatiza o êxito de sua proposta, como forma de revestir de autoridade o seu dizer, mencionado que tem mais de dez mil alunos, de vários países, que seguiram suas orientações e tiveram seus trabalhos aprovados. Após essa contextualização, passemos para as significações sobre a escrita do artigo expressas nesse vídeo, explorando, inicialmente, o terceiro passo:

Presta atenção nesse passo, por que ele é MUITO, MUITO, MUITO importante $\uparrow$ O roteiro é muito importante [...] se o seu roteiro, se o caminho de construção do seu conteúdo É RUIM, o seu trabalho vai ser ruim $\uparrow$. Por isso essa parte de planejar, roteirizar é tão importante. [...] Não saia escrevendo que nem uma "barata tonta" $\uparrow$, SAIBA O QUE VOCÊ VAI ESCREVER ((fala mais alta e com muita ênfase)) Amilton, e o quê que eu vou escrever? Montando os roteiros dos seus capítulos. Então cada capítulo do seu artigo tem que ser roteirizado [...] escolher DE 3 A 4 TÓPICOS, ESPECÍfICOS $\uparrow$ que vão direcionar o seu conteúdo [...] você pode não, VOCÊ TEM QUE fazer isso se você quiser trilhar o caminho mais rápido para produzir o seu conteúdo $\uparrow$, então o terceiro passo é roteirize os seus capítulos $\uparrow$ (Vídeo 2)

Podemos perceber que, ainda que a ideia de propor um roteiro seja um passo importante na construção de um trabalho de pesquisa, a finalidade expressa pelo enunciador é, antes de tudo, otimizar o tempo, pois propõe "roteirizar" o trabalho selecionando os conteúdos que farão com que o aluno "trilhe o caminho mais rápido" e evite escrever 
tópicos desnecessários. Assim, esse imperativo de "ter que fazer um roteiro" se apresenta, pois, como uma solução para que o estudante não precise passar dias, noites ou semanas escrevendo seu artigo.

O dizer do enunciador expressa claramente a preocupação que tem com a elaboração de um roteiro ou planejamento da escrita, enfatizando-o como uma etapa "muito, muito muito importante", já que se trata de um dos procedimentos considerados fundamentais para que o aluno tenha êxito com uma atividade de escrita em pouco tempo. Fica evidente que a preocupação é muito menos com a qualidade da produção científica do que a com a sua finalização em curto espaço de tempo, de modo a corroborar a imagem de escrita do artigo científico como uma atividade para cumprimento de uma tarefa: a aprovação do aluno.

A defesa em torno da necessidade de economizar tempo na escrita também está presente no quarto passo, que é copiar os tópicos interessantes ao pesquisar o referencial teórico, como vemos no excerto 6 :

(6)

Está aqui a - dica- > para você fazer de uma maneira direcionada e acelerada $\uparrow$ [...] QUANDO você for pesquisar $\mathbf{O} \underline{\text { SEO }} \underline{\mathbf{R E f}}$ ferencial teórico, o que você vai fazer? Você já vai LER o : referencial tirando as partes que se encaixam em cada tópico do seu roteiro $\uparrow$. Em vez de você ler tudo e começar a escrever e aí ficar que nem um MALUCO procurando onde está aquela referência? Aquela citação $\uparrow$, daquele autor que eu queria colocar aqui? NÃO, quando você ESTIVER LENDO, VOCÊ JÁ SEPARA, de preferência copia e cola em um arquivo a parte para cada tópico as citações que você encontrou $\uparrow$ [...]. DEpois, quando eu for EScrever :: , fica muito mais fácil, por que as minnhas citações estão toDAS ordenadas. (Vídeo 2)

No excerto 6, todo esforço do enunciador, para ensinar como proceder, de maneira "mais fácil", ao realizar a pesquisa do referencial teórico do trabalho, se volta ao aspecto da economia de tempo. A ênfase valorativa, expressa nos dizeres do enunciador, sustenta a defesa da realização de uma atividade de maneira "acelerada". Para a consecução desse propósito, é preciso que o aluno siga determinadas coordenadas, em que a forma de se relacionar com o referencial teórico desempenha papel determinante. Chama atenção, nesse caso, a técnica apresentada pelo enunciador sobre como proceder com as citações, a saber: "copia e cola em um arquivo a parte para cada tópico as citações que você encontrou. 
[...] depois, quando eu for escrever, fica muito mais fácil, porque as minhas citações estão todas ordenadas".

Como não expressa qualquer palavra sobre como explorar/trabalhar citações na escrita científica, a representação que se constrói, a partir desses dizeres, é que o texto científico pode se constituir como um conjunto de citações copiadas, que, uma vez ordenadas e separadas, configurarão um texto pronto. Não constatamos qualquer orientação sobre estratégias de leitura como tomar notas, resumir, sintetizar (CARLINO, 2017), nem sobre a necessidade de articular ideias/pontos de vistas dos autores lidos (MOTTA-ROTH; HENDGES, 2010), tampouco ainda sobre os riscos do copiar/colar como estratégia de diálogo com fontes que pode implicar em manifestações plagiarias na escrita acadêmicocientífico (AUTOR X, 2018). Assim, no diálogo com a literatura, o trabalho do produtor de um texto científico vai muito além da mera tarefa de recortar citações e ordená-las, para serem reproduzidas posteriormente.

No último passo apresentado pelo enunciador, que se reporta à fase de escrita do artigo científico, há um acento valorativo muito marcante na necessidade de o aluno escrever o texto sem procrastinar, como forma de render mais e produzir mais em menos tempo:

(7)

O quinto e último passo É, VAI ESCREVER MEU FILHO, que agora você já pode fazer isso $\uparrow$. Você já fez todo o seu planejamento, já têm o seu trabalho todo estruturado, então, agora escreve [...] PARA DE PROCRASTINAR ((fala com muita ênfase)) [...] e uma dica interessante: Não precisa escrever muito todo dia, porque isso desgasta, sua produtividade cai $\uparrow$. Então, se você quer aumentar sua produtividade, usa prazo curto e usa meta curta $\uparrow$, então, escreve duas página por dia, escreve uma hora por dia, você vai produzir muito mais do que você ficar QUATRO, OU CINCO HORAS se dedicando ao TCC durante todo dia para produzir. Como eu sei disso? Eu uso essa técnica, e mais de dez mil e setecentas pessoas usaram nos últimos cinco anos e estão todas aprovadas. Fizeram trabalhos muito mais rápidos, muito mais fáceis, alguns deles em sete dias $\uparrow$. Agora é a hora de escrever $\uparrow$ TEM uma técnica específica para escrever, que chama técnica ABCD, então se você é aluno já do TCC Sem Drama, quando você chegar no quinto passo, vai lá no nosso material, que esse é exclusivo $\uparrow$, só tem na área de treinamento $\uparrow[. .$.$] vê a técnica \mathrm{ABCD}$ e escreve assim [...] (Vídeo 2)

Como em excertos anteriores, a ênfase valorativa na aceleração da produção do artigo científico é reiterada aqui, dessa vez em relação à etapa de escrita do texto propriamente. $\mathrm{O}$ aluno, nos dizeres do enunciador, não pode procrastinar, devendo, pelo 
contrário, demonstrar "rendimento, produtividade", afinal, com as técnicas apresentadas, alunos que já fizeram o curso/treinamento do "TCC Sem Drama" chegaram a produzir seus TCCs "em sete dias". Compreendemos que há, pois, um posicionamento defendendo a produtividade, que, no caso, implica saber lidar com o tempo: "usa prazo curto e usa meta curta, então, escreve duas páginas por dia, escreve uma hora por dia, você vai produzir muito mais do que você ficar quatro ou cinco horas se dedicando ao TCC durante todo dia para produzir".

Podemos ver que o enunciador sinaliza uma receita de escrita (incluindo a técnica do $\mathrm{ABCD}$ citada) que compreende a concentração de esforços diários na produção do artigo científico num tempo mais curto pelo fato de representar um ganho de produtividade, aspecto recorrente na atividade acadêmica, fortemente criticado por Bianchetti (2012). Mais uma vez, portanto, a questão da técnica adotada, aliada ao desejo de controle/abreviação do tempo, é colocada como desafio para que o aluno consiga "bater" sua "meta" de produzir seu TCC e ser aprovado, reforçando, assim, mais uma vez, a representação de escrever o artigo científico para cumprir uma tarefa escolar/acadêmica, como mostrado também no estudo de Queiroz, Bessa e Jales (2015).

Cabe assinalarmos ainda que, como não se menciona que os modos de escrever um texto científico diferem conforme as áreas do conhecimento e/ou culturas disciplinares (BAZERMAN, 2014), é possível dizermos que perpassa, nesses vídeos, uma representação de escrita do artigo como um fazer homogêneo ou generalizável (RUSSEL, 2009), visão desconectada, portanto, de concepções mais atuais sobre como conceber a escrita de textos científicos, pensada como uma atividade complexa (MARTIN, 2018), que implica o domínio de um campo especializado e com função específica delimitada na comunidade acadêmica (BOSIO, 2018). É uma visão desconectada também da compreensão de que escrever um texto científico representa uma forma de aprender e de construir conhecimentos científicos (CARLINO, 2017), e não apenas uma atividade para cumprimento de uma tarefa de conclusão de curso e de recompensa da aprovação.

Com base nas representações identificadas, podemos discutir e problematizar como os dizeres expressos nesses vídeos podem se refletir/refratar nos potenciais interlocutores 
e contribuir ou não para a formação de jovens pesquisadores competentes e bem-sucedidos na escrita de artigos científicos.

Acreditamos que um primeiro aspecto a ser considerado compreende o fato de que a "mensagem" desses vídeos não tem um compromisso mais efetivo com a formação de pesquisadores, afinal, a finalidade é levar o aluno em potencial a consumir as técnicas apresentadas para cumprir a tarefa de produzir o TCC e ser aprovado. Um segundo aspecto a ser considerado é pensar que, como o foco é na pressa, com vistas a atender um aluno que se encontra em situação mais crítica de escrita quanto ao cumprimento de prazo para conclusão de curso, o uso de técnicas voltadas para o aceleramento da escrita não condiz com a experiência e a vivência de uma situação autêntica de interlocução, na qual estaria implicada uma produção científica de qualidade e comprometida com a produção de conhecimentos.

Por fim, cabe destacarmos que, se concebida não como atividade de aprendizado, de construção de conhecimentos e de contribuir com a área do saber, as orientações, técnicas e/ou dicas apresentadas podem cumprir os propósitos pretendidos. Logo, ainda que alunos do curso/treinamento do "TCC Sem Drama” possam obter notas 9,0, 9,5 e 10,0, não significa que eles tenham conseguido dominar a escrita do artigo científico e possam ser considerados produtores competentes e bem-sucedidos, até porque, como nos lembram Bazerman (2014) e Russel (2009), o aprendizado da escrita científica não cessa e não se reduz ao domínio de algumas técnicas. Pressupõe tempo...tempo para a pesquisa, a organização e sistematização de ideias, o planejamento da textualização, o ato de escrever, a revisão, a reescrita, a publicação. Pressupõe também tempo para um ensino sistemático e contínuo, conforme sinaliza Carlino (2017).

\section{Conclusão}

Partindo da compreensão de que se constitui um desafio, para nós estudiosos da linguagem, lançarmos olhares investigativos sobre as redes de dizeres e sentidos que são tecidas e que circulam no universo digital a respeito das práticas de leitura e escrita, objetivamos, neste trabalho, analisar representações sobre a escrita científica expressos em vídeos 
do YouTube destinados a apresentar dicas e/ou orientações acerca de como escrever/produzir artigos científicos.

Como objetivos específicos, estabelecemos os seguintes: i) verificar como a escrita desse gênero acadêmico-científico é significada nos vídeos recortados para análise; ii) discutir como representações sobre a escrita científica construídas, nesses vídeos, podem ou não colaborar com a formação de jovens pesquisadores competentes e bem-sucedidos na escrita de artigos científicos.

Para o desenvolvimento desse empreendimento investigativo, buscamos respaldar nossas reflexões em ideias de pensadores do Círculo de Bakhtin sobre o funcionamento dialógico e ideológico da linguagem e em trabalhos de estudiosos que abordam a escrita científica em perspectiva enunciativa e sociorretórica. Ancorados nesses horizontes teóricos, realizamos um estudo de natureza interpretativa e de base qualitativa de dois vídeos do YouTube do canal "TCC Sem Drama" destinados a apresentar dicas e/ou orientações sobre como escrever/produzir artigos científicos.

Nossa leitura interpretativa aponta que a escrita científica é significada, nesses vídeos, como um produto que apresenta uma estrutura fixa, homogênea e generalizável a ser apreendida/dominada por um conjunto de técnicas concebidas para cumprir, dentro de um reduzido espaço de tempo, uma tarefa meramente escolar/acadêmica, de atribuição de nota, tendo como foco a conclusão do curso.

Aponta, ademais, que, como as representações sobre a escrita do artigo científico construídas não dão conta de conceber a escrita científica como uma atividade complexa (MARTIN, 2018), de aprendizado processual e contínuo, não redutível a um domínio de técnicas e/ou dicas, esses vídeos não se constituem em fonte de consulta/leitura/formação plenamente satisfatória e confiável para que pesquisadores iniciantes e jovens pesquisadores possam se tornar competentes e bem-sucedidos na escrita de artigos científicos.

Assim, destacamos que, se entendemos que as orientações examinadas aqui, como muitas outras que circulam no universo digital, podem ser úteis em alguma medida, especialmente quando levamos em conta a situação de escrita pressuposta (dramática) e a finalidade pretendida (de aprovação do TCC) por aqueles que por elas se interessam, alertamos, 
contudo, que, num universo digital com tantas possibilidades de pesquisa e formação, essas “orientações” não podem ser tomadas como única fonte de consulta por aqueles que se preocupam com uma escrita de textos científicos de qualidade, realizada dentro de situações autênticas de interação e comprometida com o fazer científico e a construção de conhecimentos.

Reforçamos, pois, a importância e a necessidade dos investimentos nos letramentos acadêmicos, nos termos defendidos por Burton e Chadwick (2000), como possibilidade de contribuir com a formação de pesquisadores iniciantes e jovens pesquisadores, especialmente, no sentido de lhes oferecer habilidades de seleção e avaliação crítica de conteúdos disponíveis no universo digital, assim como da apropriação produtiva desses conteúdos para o aprendizado e a construção de conhecimentos.

\title{
REPRESENTATIONS ABOUT THE SCIENTIFIC WRITING ON YOUTUBE VIDEOS
}

\begin{abstract}
Based on the need to discuss issues related to reading and writing in higher education in the context of digital technologies, this article aims to analyze representations about scientific writing expressed in YouTube videos. Assuming an interpretive view and a qualitative approach, the study focuses on examining two videos from the YouTube channel "TCC Sem Drama" intended to provide guidance on how to write scientific articles. The theoretical basis includes ideas from thinkers and commentators from the Bakhtin Circle and works by scholars who approach scientific writing in an enunciative and /or socio-rhetorical perspective. The analysis points out that scientific writing is meant, in these videos, as a product that has a fixed, homogeneous and generalizable structure, which can be learned through a set of techniques designed to fulfill, within a short space of time, a mere academic task /obligation.
\end{abstract}

KEYWORDS: Scientific article; Scientific writing; YouTube channel.

\section{REFERÊNCIAS}

ASSOCIAÇÃO BRASILEIRA DE NORMAS TÉCNICAS - ABNT. 2018. NBR 6022: informação e documentação: artigo em publicação periódica científica impressa - apresentação. Rio de Janeiro: ABNT.

ATALLAH, Mariana de Castro; NOGUEIRA, Mayara de Oliveira. "E eu tô aqui sofrendo": uma entrevista e os vários fenômenos sociolinguísticos interacionais. Percursos linguísticos, v. 3, n. 7, p. 1-21, 2013. 
AVELINO, Bruna Camargos. Olhando-se no espelho: uma investigação sobre o Narcisismo no ambiente acadêmico. 2017. 206f. (Tese de Doutorado em Controladoria e Contabilidade) - Faculdade de Economia, Administração e Contabilidade da Universidade de São Paulo, São Paulo, 2017.

AZZARI, Eliane Fernandes. EFL collaborative writing: text production and online resources. Diálogo das Letras, v. 8, n. 1, p. 52-65, jan./abr. 2019.

BAKHTIN, Mikhail. Por uma metodologia das ciências humanas. Organização, tradução, posfácio e notas de Paulo Bezerra. São Paulo: Editora 34, 2017, p. 57- 79.

BAKHTIN, Mikhail. Os gêneros do discurso. In: BAKHTIN, M. Os gêneros do discurso. Organização, tradução, posfácio e notas de Paulo Bezerra. São Paulo: Editora 34, p. 11-69. 2016.

BAKHTIN, Mikhail. Problemas da poética de Dostoiévski. Tradução de Paulo Bezerra. $5^{\mathrm{a}}$ ed. Rio de Janeiro: Forense Universitária, 2015.

BAZERMAN, Charles. El descubrimento de la escritura acadêmica. Traducción de Natalia Ávila Reye. In: NAVARRO, Federico. (Coord.). Manual de escritura para carreras de bumanidades. Ciudad Autónoma de Buenos Aires: Editorial de la Facultad de Filosofía y Letras Universidad de Buenos Aires, 2014. p. 11-16.

BERNARDINO, Cibele Gadelha; COSTA, Raquel Leite Saboia. A metodologia de artigos acadêmicos em diferentes culturas disciplinares. Fórum Linguístico, v. 14, p. 2666-2684. 2017.

BERNARDINO, Cibele Gadelha; COSTA, Raquel Leite Saboia. A introdução de artigos acadêmicos e as diferenças entre culturas disciplinares. Intersecções, v. 9, p. 151-170. 2016. BESSA, José Cezinaldo Rocha. Dialogismo e construção da voz autoral na escrita do texto cientifico de jovens pesquisadores. 2016, 385 f. Tese (Doutorado em Linguística e Língua Portuguesa) Universidade Estadual Paulista "Júlio de Mesquita Filho" - Faculdade de Ciências e Letras (Campus Araraquara), 2016a.

BESSA, José Cezinaldo Rocha. O discurso citado na macroestrutura textual de artigos científicos de jovens pesquisadores. Ilha do Desterro, v. 69, p. 45, $2016 \mathrm{~b}$.

BESSA, José Cezinaldo Rocha; BERNARDINO, Rosângela Alves dos Santos. Equívocos em torno da escrita: o caso das dicas de produção de textos em vídeos do You'Tube. Dominios de Lingu@Gem, v. 11, n. 1, p. 174 - 191, 2016.

BOCH, Françoise; GROSSMANN, Francis. Referir-se ao discurso do outro: alguns elementos de comparação entre especialistas e principiantes. Scripta, v. 6, n. 11, p. 97-108. 2002.

BOSIO, Iris Viviana. ¿Podemos mejorar la calidad de la escritura en el posgrado? Algunas respuestas a partir de un proceso de investigación-acción. Rev. Bras. Linguíst. Apl., v. 18, n. 4, p. 737-769. 2018.

BRAIT, Beth; MELO, Rosineide de. Enunciado/enunciado concreto/enunciação. In: BRAIT, B. (org.). Bakhtin: outros conceitos-chave. São Paulo: Contexto, p. 61-78. 2010. BRASIL. Ministério da Educação. Base Nacional Comum Curricular-BNCC. 2018. Brasília, MEC. Disponível em: http://basenacionalcomum.mec.gov.br/images/BNCC_EI_EF_110518_versaofinal_site.pdf. Acesso em: 15 dez. 2018. 
BURTON, Vicki Tolar.; CHADWICK, Scott. A. Investigating the practices of student researchers: patterns of use and criteria for use of internet and library sources. Computers and Composition, v. 17, n. 3, p. 309-328. 2000.

CARLINO, Paula. Escrever, ler e aprender na universidade - uma introdução à alfabetização acadêmica. Petropolis: Vozes, 2017.

CORACINI, Maria José Rodrigues Faria. Um fazer persuasivo: o discurso subjetivo da Ciência. $2^{\mathrm{a}}$ ed. Campinas: Pontes, 2007.

DANTAS, S. G. M.; LIMA, S. C. de. A escrita colaborativa no Google Docs: uma proposta de ensino do gênero textual factual recount no ensino técnico de nível médio integrado. Diálogo das Letras, v. 8, n. 3, p. 157-176. 2019.

DAY, Robert A. Como escrever e publicar um artigo cientifico. Tradução de Marina André de Alvarez. $5^{a}$ ed. São Paulo: Livraria e Editora Santos, 2001.

GARCIA NEGRONI, María Marta. Subjetividad y discurso científico-académico: acerca de algunas manifestaciones de la subjetividad en el artículo de investigación en español. Rev. Signos, v. 41, n. 66, p. 9-31. 2008.

HYLAND, Ken. Disciplinary discourses: social interactions in academic writing. Michigan: The University of Michigan Press, 2004.

HYLAND, Ken. Dialogue, persuasion and community in research writing. In: GIL-SALOM, Luz; SOLER-MONREAL, Carmen. (eds.). Dialogicity in Written Specialised Genres. Amsterdam: John Benjamins, 2014.

KENSKI, Vani Moreira. Educação e comunicação: interconexões e convergências. Educ. Soc., v. 29, n. 104, p. 647-665. 2008.

KENSKI; Vani Moreira. Aprendizagem mediada pela tecnologia. Revista Diálogo Educacional, v. 4, n. 10, p. 47-56. 2003.

KERSCH, Dorotea Frank; MARQUES, Renata Garcia. Redes sociais digitais na escola: possibilidades de conexão, produção de sentido e aprendizagem. Diálogo das Letras, v. 6, n. 2, p. 343-362. 2017.

LAVILLE, Christian; DIONNE, Jean. A construção do saber: manual de metodologia da pesquisa em ciências humanas. Tradução de Heloísa Monteiro e Francisco Settineri. Portalegre: Artes Médicas, Sul Ltda.; Belo Horizonte: Editora UFMG, 1999.

LODER, Letícia Ludwig; JUNG, Neiva Maria. (org.). Análises em fala-em-interação institucional: a perspectiva da análise da conversa etnometodológica. Campinas: Mercado de Letras, 2009.

MACHADO, A. M. N. Do modelo ao estilo: possibilidades de autoria em contextos acadêmico-científicos. In: CALIL, E. (org.). Trilhas da escrita: autoria, leitura e ensino. São Paulo: Cortez, 2007. p. 171-207.

MARTÍN, Eloísa. Ler, escrever e publicar no mundo das ciências sociais. Revista Sociedade e Estado, v. 33, n. 3, p. 941-961. 2018.

MCCLURE, Randall; CLINK, Kellian. How Do You Know That? An Investigation of Student Research Practices in the Digital Age. Libraries and the Academy, v. 9, n. 1, p. 115132. 2009. 
MEDVIÉDEV, Pável Nikoláevitch. O método formal nos estudos literários: introdução crítica a uma poética sociológica. Tradução de Ekaterina Vólkova Américo e Sheila Camargo Grillo. São Paulo: Contexto, 2012.

MORAN, José Manuel. Como utilizar a internet na educação. Ciência da Informação, v. 26, n. 2, p. 1-8. 1997.

MOTTA-ROTH, Désirée; HENDGES, Gaciela Rabuske. Produção textual na universidade. $1^{a}$ ed., São Paulo: Parábola Editorial, 2010.

NAVARRO, Federico; BROW, Ana. Lecture y escritura de géneros académicos: conceptos básicos. In: NAVARRO, Federico. (coord.). Manual de escritura para carreras de humanidades. Ciudad Autónoma de Buenos Aires: Editorial de la Facultad de Filosofía y Letras Universidad de Buenos Aires, 2014. p. 55-100.

OKADA, Alexandra. O que é cartografia cognitiva e por que mapear redes de conhecimento. In: OKADA, Alexandra. (org.). Cartografia cognitiva: mapas do conhecimento para pesquisa, aprendizagem e formação docente, Cuiabá: KCM, 2008. p. 37-65.

QUEIROZ, Maria Eliete de; BESSA, José Cezinaldo Rocha; JALES, Adriana Morais. Os significados de escrever no ensino superior: a produção textual no discurso de professores e alunos de um curso de Letras. Alfa, v. 59, n. 3, p. 523-538, 2015.

RIBEIRO, Ana Elisa. Que futuros redesenhamos? Uma releitura do manifesto da Pedagogia dos Multiletramentos e seus ecos no Brasil para o século XXI. Diálogo das Letras, v. 9, p. 1-19, e02011, 2020.

RUSSEL, D. Letramento acadêmico: leitura e escrita na universidade: entrevista com David Russel. Entrevista concedida a Flávia Brocchetto Ramos e Vânia Marta Espeiorin. Conjectura, v. 14, n. 2, p. 214-247. 2009.

SACKS, H., SCHEGLOFF, Emanuel. A.; JEFFERSON, Gail. A simplest systematic for the organization of turn-taking for conversation. Language Baltimore, v. 50, n. 4, p. 696735. 1974.

SEVERINO, Antônio Joaquim. A educação e universidade. Interfaces - Comunic, Saúde, Edc, v. 6, n. 10, p. 117-124. 2002.

SOBRAL, Aldair. Do dialogismo ao gênero: as bases do pensamento do Círculo de Bakhtin. Campinas: Mercado das letras, 2009.

SWALES, Jonh. Genre analysis: english in academic and research settings. Cambridge: CUP, 1990.

VALENTE, José Armando. A comunicação e a educação baseada no uso das tecnologias digitais de informação e comunicação. Revista UNIFESO: humanas e sociais, v. 1, n. 1, p. 141-166. 2014.

VOLÓCHINOV, Valentim. Marxismo e filosofia da linguagem: problemas fundamentais do método sociológico na ciência da linguagem. Tradução de Sheila Grillo e Ekaterina Vólkova. São Paulo: Editora 34, 2017.

Recebido em: 16/07/2020.

Aprovado em: 19/11/2020. 